\title{
Yapım İşlerinde Çalışanların Kişisel Koruyucu Donanım Kullanımına Etki Eden Faktörler
}

\author{
Şahin Tolga GÜVEL ${ }^{* 1}$, Emel LAPTALI ORAL ${ }^{2}$ \\ ${ }^{1}$ Osmaniye Korkutata Üniversitesi, Mühendislik Fakültesi, İnşaat Mühendisliği Bölümü, \\ Osmaniye \\ ${ }^{2}$ Çukurova Üniversitesi, Mühendislik Fakültesi, İnşaat Mühendisliği Bölümü, Adana
}

Geliş tarihi: 24.02.2021 Kabul tarihi: 30.06.2021

Öz

İnşaat sektörü, iș kazalarının çok görüldüğü sektörler arasında yer almaktadır. İș kazalarının önlenmesi için; işyerinin risk değerlendirme raporuna göre belirlenecek uygun kişisel koruyucu donanımın (KKD) çalışanlar tarafından kullanılması önemlidir. Bu çalışmada inşaat sektöründe çalışanların KKD kullanımlarına etki eden faktörler ele alınmıştır. Bu amaçla yapılan anket çalışmasından elde edilen veriler kullanılarak yapılan analizler sonucunda, bu faktörlerin KKD kullanımı üzerindeki etkileri değerlendirilmiş̧ir.

Anahtar Kelimeler: İşs sağlığı ve güvenliği, İnşaat sektörü, KKD kullanımı, İş kazası

\section{Factors Affecting Personal Protective Equipment Usage of Construction Workers}

\begin{abstract}
Construction is one of the infamous sectors in occupational accidents. Personal protective equipment (PPE) usage which is determined by the risk evaluation report of construction site is a very important factor in preventing occupational accidents. On this study, factors affecting construction workers' PPE usage were examined through a questionnaire survey and analysis of the collected data.
\end{abstract}

Keywords: Occupational health and safety, Construction sector, PPE usage, Work accident

*Sorumlu yazar (Corresponding author): Şahin Tolga GÜVEL, stolgaguvel@yahoo.com 


\section{GIiRiş}

İnşaat sektörü; yapım sürecinde birbirinden farklı ekiplerin işin ilerleyişine bağlı olarak sürekli yer değiştirerek çalışmaları, bu süreç boyunca yapının sürekli değişimininden kaynaklı iş ile ilgili risklerin sürekli değişmesi nedeniyle çalışma ortamı güvenliğinin sağlanmasının çok zor olduğu bir sektördür. Buna ek olarak iş devrinin yoğun olması sebebiyle sık ekip değişimi yaşanması da iş kazası riskini arttıran başka bir faktördür. İş kazalarının önlenmesinde asıl hedef ortam güvenliğini toplu koruma yöntemleri ile sağlamak olmakla birlikte, bunun mümkün olmadığı yerlerde iş kazalarının önlenmesi için en etkili yöntem, çalışanların işe uygun KKD kullanımıdır.

İş sağlığı ve güvenliği ile ilgili Türkiye'de çeşitli yasal düzenlemeler yapılmıştır. Bunlardan en önemlisi 6331 Sayılı İş Sağlığı ve Güvenliği Kanunudur. Bu kanuna dayanılarak; 2012 yılı sonrasında iş sağlığ1 ve güvenliği ile ilgili peyder pey düzenlemeler yapılmıştır. Yürürlüğe giren yasal düzenlemeler yeterli görünmektedir. Ancak yapılan araştırmalarda, yasal mevzuatın inşaat sektöründe beklenen seviyede uygulanamadığı görülmektedir [1-9]. İnşaat sektörü; kendine ait şartları ve yasal mevzuatla getirilen düzenlemelere hazır olmaması sebebiyle, iş kazaları yönünden halen en riskli sektörler arasındadır. İş sağlığı ve güvenliği yönünden inşaat sektörünün istenen düzeye gelmesi zaman alacaktır.

\section{2. ÖNCEKİ ÇALIŞMALAR}

İş kazaları ve çalışanların KKD kullanımı ile ilgili çeşitli faktörler, bir çok araştırmada incelenmiştir. Literatür bulgularına göre işyerlerinde KKD kullanımı iş güvenliğine verilen önemin bir göstergesi olarak değerlendirilmektedir. İş kazası geçirme açısından riski en yüksek grup olarak da KKD kullanmayan çalışanlar görülmektedir. Dorji ve Hadikusomo [1] tarafından Hong Kong'da yapılan bir çalışmada; baret kullanım oranı $\% 87,5$; eldiven kullanım oranı \%80; gözlük kullanım oranı $\% 77,5$; ayakkabı kullanım oranı \% 70; yüz koruyucu kullanım oranı \%56; emniyet kemeri kullanım oranı $\% 50$; solunum maskesi kullanım oranı \%37,5; kulak tıkacı kullanım oranı \%20 olarak belirlenmiştir. Türkiye'de yapılan bir çalışmada, çalışanların iş güvenlikleri için emniyet kemeri, baret ve eldiven kullanması oranı \%46, kullanmaması oranı \%46 seviyesinde görülmüştür. $\% 8$ oranında çalışanın bu konu ile ilgili fikri bulunmamaktadır. Kuruoğlu ve arkadaşları [2] tarafından yapılan araştırmada iş güvenliği ve sağlığı risk değerlendirmesinde KKD kullanımına kesinlikle katılmayan çalışanlar, en riskli gruplar arasında tespit edilmiştir.

İş güvenliğinin sağlanmasında en önemli etkenlerden biri denetimdir. Laitinen ve Ruohomaki [3] tarafından Finlandiya' da bir çalışma yapılmıştır. Çalışmada performans yönetimine bağlı bir hafta süreli denetim yönteminden sonra iki inşaat şantiyesinde denetmenlerin ve çalışanların iş güvenliği uygulama seviyesi gözlemlenmiştir. Çalışmanın sonunda elde edilen geri bildirimlerle birinci şantiyede indeks seviyesinin \%60'dan $\% 89$ 'a, ikinci şantiyede indeks seviyesinin $\% 67$ 'den \%91 düzeyine çıktığı tespit edilmiştir. Dikmen vd. [4] tarafından yapılan araştırmada Türkiye inşaat sektöründe yer alan uygulamalarla alakalı yapılan çalışmaya göre, inşaat projelerinin yalnız \%42,3'ünün iş sağlığ1 ve güvenliği konusunda resmi kurumlar tarafindan denetim gördüğü tespit edilmiştir.

Yapılan araştırmalara göre iş güvenliği eğitiminin verilmesi oranı yükseldikçe, iş kazasının meydana gelme riski azalmaktadır. Ancak iş güvenliği ile ilgili eğitim verilmesi oranı çok düşük seviyededir. Zhou ve arkadaşları [5] tarafından yapılan bir araştırmaya göre; iş güvenliğinin sağlanmasında en etkili ilk dokuz faktör arasında ikinci sırada iş güvenliği danışmanlığı ve eğitimi yer almaktadır. Hassanein ve Hanna [6] tarafından yapılan diğer bir çalışmada firmaların \%20'sinin işçileri gayri resmi oryantasyon eğitimi ile işe aldığı, diğer \%20 firmanın, çalışanlarına resmi oryantasyon eğitimi verdiği, işçilerin \%60'ına ise hiç oryantasyon eğitimi verilmediği belirlenmiştir. Şirket içi iş sağlığı ve güvenliği eğitimi, kişisel sağlık ve güvenliğin korunmasına yardım etmektedir ve firmayı kişisel güvenlikten dolayı ortaya çıkacak olumsuzluklara karşı korumaktadır. Ho ve Dzeng, 
[7] tarafından iş güvenliği eğitiminin etkileri üzerine yapılan bir araştırmada; iş güvenliği eğitiminin iş kazalarını azaltmada yararlı olduğu, 2001 yılı ile 2008 yılı arasında iş güvenliği eğitimine bağlı iş kazalarında \%14,57'lik azalma olduğu tespit edilmiştir. Fakat aynı araştırma sonuçları işçilerin \%67,82' sinin iş güvenliği eğitimi almadığını göstermektedir. Metinsoy ve Müngen [8] tarafından yapılan bir başka anket çalışmasının neticeleri de, iş güvenliği eğitimi ile ilgili bir çok eksikliğin olduğunu göstermektedir. İşçilerin çoğunun detaylı bir eğitimi bulunmamaktadır. Dikmen ve arkadaşları [4] tarafından yapılan bir anket çalışmasında alınan cevaplarda şirket içi eğitimlerin periyodik olarak verilmesi $\% 50$ seviyesinde iken, şirket içi eğitim verilmemesi \%34 seviyesindedir. Yanıtların \%97'si yeni çalışanlara mutlaka iş sağlığ ve güvenliği eğitimi verildiği yönündedir. Etkin bir iş güvenliği eğitimi ile kaza sayılarında büyük ölçüde azalma sağlanabileceği düşünülmektedir. Demirkesen ve arkadaşları [9] tarafından yapılan araştırmada Amerikan İş Güvenliği ve Sağlığı İdaresi'nin (OSHA) 20002007 yılı kayıtlarına göre, düzenli olarak yürütülen iş güvenliği eğitimleri ile iş kazaları sonucu meydana gelen ölüm, yaralanma ve hastalık oranlarında düşüşs sağlandığı gözlemlenmektedir.

Siu ve arkadaşları [10] tarafından Hong Kong inşaat işçilerinin yaşa bağlı iş güvenliği performansını değerlendiren çalışmaya göre; kazalar ile çalışan yaşı arasında bir bağlantı olmamakla birlikte, kişisel yaralanmalar ile çalışan yaşı arasında eğrisel bir bağlantı bulunmaktadır. Yaşı daha fazla olan çalışanlar, genç çalışanlara göre iş güvenliği gereklerine daha olumlu yaklaşmakta ve deneyime bağlı olarak kaza oranı da azalmaktadır. Manisalı ve arkadaşları [11] tarafından Türkiye'de yapılan bir araştırmada 2002 ve 2005 yılları arasında ölümlü iş kazalarının yaşlara göre dağılımını incelenmiş, en çok ölümlü iş kazası ile karşılaşılan grup olarak 3034 yaş grubu tespit edilmiştir. Bu gruptan sonra sırası ile 25-29 yaş, 35-39 yaş ve 40-44 yaş grupları gelmektedir. Sürekli iş göremezlikle sonuçlanan iş kazalarında çalışan yaş dağılımına göre en çok sürekli iş göremezlik ile karşılaşılan grup olarak 3539 yaş grubu görülmektedir. Bu yaş grubunu 30-34 yaş, 40-44 yaş ve 25-29 yaş grupları takip etmektedir. İş kazaları ile çalışan yaşı arasında net bir bağlantı bulunmamakla birlikte, genel olarak çalışan yaşının artması ile iş kazası geçirme oranının düştüğü görülmektedir.

Yapım işlerinde çalışanların KKD kullanımını etkileyen birçok faktör bulunmakla birlikte bu çalışmada; çalışan yaşı, iş güvenliği eğitimi ve iş güvenliği denetim sıklığı faktörlerinin, KKD kullanımına etkileri incelenmiştir. $\mathrm{Bu}$ amaçla yapılan anket çalışmasıyla ulaşılan sonuçlar, SPSS istatistik programıla analiz edilerek, söz konusu faktörlerin KKD kullanımı üzerindeki etkileri değerlendirilmiştir.

\section{MATERYAL VE METOT}

Bu çalışmada, çalışanların KKD kullanımına etki eden faktörleri belirlemek amacıyla; Türk inşaat sektöründe ISG uygulamalarını konu alan bir doktora çalışmasına ait anket formu kullanılmıştır [12]. Hazırlanan anketler 2013 yılı Ocak ve Nisan ayları arasındaki dönemde Türkiye genelinde dağıtılmıştır. 2013 yılı Temmuz ayına kadarki dönemde toplam 234 adet anketten değerlendirmeye uygun geri dönüş alınmıştır. Anket çalışmasından sağlanan sonuçlar, geçmişte yapılan çalışmalarınn verileri ve yasal mevzuat dikkate alınarak değerlendirilmiştir. Ayrıca anket sonuçlarının, SPSS paket programı kullanılarak ANOVA ve Ki Kare analizleri yapılmıştır. Analiz sonuçlarına göre yapım işlerinde çalışanların KKD kullanımına etki eden faktörler belirlenmeye çalışılmıştır.

\section{BULGULAR VE TARTIŞMA}

\subsection{Yaş Dağılımı}

Ankete katılan grupların yaş dağılımlarının verildiği Çizelge 1 incelendiğinde; katılımcıların en fazla 25 ile 34 yaş arasında olduğu görülmekle birlikte, 50 yaş üstü çalışan oranındaki hızlı düşüş ve özellikle 60 yaş ve üzerindeki \%0,43'lük oran inşaat sektöründeki çalışma şartlarının, bedensel güç gerektiren ağır iş grubu olmasının bir göstergesi kabul olarak edilebilir. 
Çizelge 1. Yaş dağılımı

\begin{tabular}{|c|c|c|c|}
\hline $\begin{array}{c}\text { Sıra } \\
\text { no }\end{array}$ & Yaş dağılımı & $\begin{array}{c}\text { Katılımcı } \\
\text { sayısı }\end{array}$ & $\begin{array}{c}\text { Oranı } \\
(\boldsymbol{\%})\end{array}$ \\
\hline 1 & $18-19$ Yaş & 3 & 1,28 \\
\hline 2 & $20-24$ Yaş & 17 & 7,42 \\
\hline 3 & $25-29$ Yaş & 41 & 17,52 \\
\hline 4 & $30-34$ Yaş & 48 & 20,51 \\
\hline 5 & $35-39$ Yaş & 39 & 16,67 \\
\hline 6 & $40-44$ Yaş & 35 & 14,96 \\
\hline 7 & $45-49$ Yaş & 27 & 11,54 \\
\hline 8 & $50-54$ Yaş & 13 & 5,56 \\
\hline 9 & $55-59$ Yaş & 5 & 2,14 \\
\hline 10 & 60 Yaş ve Üzeri & 1 & 0,43 \\
\hline 11 & Belirtilmemiş & 5 & 2,14 \\
\hline & TOPLAM & $\mathbf{2 3 4}$ & $\mathbf{1 0 0 , 0 0}$ \\
\hline
\end{tabular}

\subsection{Kişisel Koruyucu Donanım (KKD) Kullanımı}

Çalışanlar işyerinde kendilerine verilen KKD'leri kullanmakla, işverenler çalışanlara yapılan işle ilgili KKD'leri kullandırmakla sorumludurlar (Kişisel Koruyucu Donanımların İşyerlerinde Kullanılması Hakkında Yönetmelik, İş Sağlığı ve Güvenliği Hizmetleri Yönetmeliği, İş Sağlı̆̆ ve Güvenliği Kanunu, Yapı İşlerinde İş Sağlığı ve Güvenliğgi Yönetmeliği) [13-16]. İnşaat işlerinde genel teamül; tüm çalışanlar tarafından baret ve iş ayakkabısının inşaat sahası içinde kullanılması şeklindedir. Diğer KKD'ler ise, yapılan işe, saha şartlarına ve risk değerlendirmeye göre belirlenmektedir (Kişisel Koruyucu Donanımların İşyerlerinde Kullanılması Hakkında Yönetmelik) [13].

Anket sonuçlarına göre; çelik burunlu iş ayakkabısı kullanımı \%68,80, çalışanların baret kullanımı $\% 67,95$, KKD'yi hiç kullanmayanların ise \%7,26 seviyesinde olduğu görülmüştür (Çizelge 2).

Çizelge 2. Örneklemin KKD kullanım oranları

\begin{tabular}{|c|l|c|c|}
\hline $\begin{array}{c}\text { Sira } \\
\text { no }\end{array}$ & KKD & $\begin{array}{c}\text { Kullanan } \\
\text { sayıSı }\end{array}$ & $\begin{array}{c}\text { Oranı } \\
(\mathbf{\%})\end{array}$ \\
\hline 1 & İş Ayakkabısı & 161 & 68,80 \\
\hline 2 & Koruyucu Eldiven & 160 & 68,38 \\
\hline 3 & Baret & 159 & 67,95 \\
\hline 4 & Yelek & 130 & 55,56 \\
\hline 5 & Toz Maskesi & 102 & 43,59 \\
\hline 6 & Koruyucu Gözlük & 101 & 43,16 \\
\hline 7 & Emniyet Kemeri & 91 & 38,89 \\
\hline 8 & Hiçbiri & 17 & 7,26 \\
\hline & TOPLAM & $\mathbf{2 3 4}$ & $\mathbf{1 0 0 , 0 0}$ \\
\hline
\end{tabular}

\section{3. İş Güvenliği Denetimleri}

İş güvenliği ile ilgili denetimleri yapmak işverenin sorumlulukları arasında yer almaktadır. İşveren, kendine ait bu sorumluluğu iş güvenliği uzmanları aracılığıyla gerçekleştirebilir. İş̧ güvenliği uzmanlarından, görev aldıkları işyerindeki iş güvenliği denetimlerini yasal mevzuata uygun olarak yapmaları beklenmektedir (İş Sağllğı ve Güvenliği Kanunu, Yapı İşlerinde İş Sağlığı ve Güvenliği Yönetmeliği, Yap1 Müteahhitlerinin Sinıflandırılması ve Kayitlarının Tutulması Hakkında Yönetmelik, Şantiye Şefleri Hakkında Yönetmelik, İş Güvenliği Uzmanlarının Görev Yetki Sorumluluk ve Eğitimleri Hakkında Yönetmelik) [15-19].

Mevzuatın gerekliliklerine karşılık, ankete katılanların çalıştıkları şantiyelerde iş güvenliği denetimleri incelendiğinde; şantiyelerin $\% 14,53$ 'ünde mevzuata uygun iş güvenliği denetimi hiç yapılmazken, günlük iş güvenliği denetim oranının yalnızca \%44,44 seviyesinde olduğu görülmektedir (Çizelge 3).

Çizelge 3. Şantiyede İSG denetim sıklığı

\begin{tabular}{|c|l|c|c|}
\hline Sıra no & $\begin{array}{l}\text { ISG denetim } \\
\text { sıklığı }\end{array}$ & $\begin{array}{c}\text { Katılımcı } \\
\text { SayıSı }\end{array}$ & $\begin{array}{c}\text { Oranı } \\
(\boldsymbol{\%})\end{array}$ \\
\hline 1 & Yapılmıyor & 34 & 14,53 \\
\hline 2 & Günlük & 104 & 44,44 \\
\hline 3 & Haftalık & 50 & 21,37 \\
\hline 4 & Aylık & 36 & 15,38 \\
\hline 5 & Belirtilmemiș & 10 & 4,27 \\
\hline & TOPLAM & $\mathbf{2 3 4}$ & $\mathbf{1 0 0 , 0 0}$ \\
\hline
\end{tabular}

\section{4. İş Güvenliği Eğitimleri}

İşverenler çalışanlara; işe başlamalarından önce, iş veya çalışma yerinde değişiklik olduğunda, iş ekipmanları değiştiğinde, yeni bir teknoloji uygulandığı zaman ve çok tehlikeli sınıf içinde bulunan işlerde senede en az bir kez iş güvenliği eğitimi verilmesi ile sorumludurlar (İş Sağlığı ve Güvenliği Yönetmeliği, 6331 Sayılı İş Sağlığı ve Güvenliği Kanunu, Çalışanların İş Sağlığı ve Güvenliği Eğitimlerinin Usul ve Esasları Hakkında Yönetmelik). 
Anket sonuçlarına göre yapım işlerinde çalışanlara iş güvenliği eğitimi verilmesi oranları; işe başlanmasından önce \%67,52, çalışma yerinde değişik olduğunda \%10,26, yeni makine gelince $\% 13,25$ olarak görülmektedir. Senede en az bir kez eğitim verilmesi oranı ise; her 6 ayda 1 defa $\% 10,68$ ve yılda 1 defa $\% 1,71$ olmak üzere toplamda $\% 12,39$ olarak hesaplanmaktadır. (Çizelge 4).

Çizelge 4. İSG eğitimi verilme zamanı

\begin{tabular}{|c|l|c|c|}
\hline $\begin{array}{c}\text { Sira } \\
\text { no }\end{array}$ & $\begin{array}{l}\text { ISG eğitim verilme } \\
\text { zamanı }\end{array}$ & $\begin{array}{c}\text { Katılımcı } \\
\text { sayısı }\end{array}$ & $\begin{array}{c}\text { Oranı } \\
(\mathbf{\%})\end{array}$ \\
\hline 1 & İşbaş1 Öncesinde & 158 & 67,52 \\
\hline 2 & Verilmez & 32 & 13,68 \\
\hline 3 & Yeni Makine Gelince & 31 & 13,25 \\
\hline 4 & Her 6 Ayda 1 Defa & 25 & 10,68 \\
\hline 5 & Yer Değişiminde & 24 & 10,26 \\
\hline 6 & İşbaş1 Sonrasında & 18 & 7,69 \\
\hline 7 & Belirtilmemiş & 6 & 2,56 \\
\hline 8 & Y1lda 1 Defa & 4 & 1,71 \\
\hline & TOPLAM & $\mathbf{2 3 4}$ & $\mathbf{1 0 0 , 0 0}$ \\
\hline
\end{tabular}

\subsection{Hipotez Testleri}

\subsection{1. Çalışan Yaşının KKD Kullanımına Etkisi}

Çalışanların yaşı ile KKD kullanımı arasındaki ilişki, Anova testi kullanılarak analiz edilmiştir. Çalışan yaşının KKD kullanımına etkisi ile ilgili hipotezler aşağıda verilmiştir.

$\mathrm{H}_{0}$ : Çalışanların yaşı ile KKD kullanımları arasında anlamlı bir ilişki yoktur.

$\mathrm{H}_{1}$ : Çalışanların yaşı ile KKD kullanımları arasında anlamlı bir ilişki vardır.

Yukarıda belirtilen $\mathrm{H}_{0}$ hipotezi öncelikle tüm grupların cevaplarının toplamı baz alınarak daha sonra da 5 grup ayrı ayrı ele alınarak test edilmiştir.

Çalışanının üçer yaş aralıkla oluşturulan dağılım tabloları, çalışan yaşının KKD kullanımına etkisinin olmadığını göstermektedir.

Çizelge 5'de görüldüğü gibi Sig (p) değeri 0,596 $\% 95$ güven aralığında değerlendirildiğinde 0,05 değerinden büyük olduğu için $\mathrm{H}_{0}$ hipotezi kabul edilerek çalışanların yaşı ile KKD kullanımları arasında anlamlı bir ilişki olmadığı sonucuna varılmaktadır.
Çizelge 5. Çalışan yaşının KKD kullanımına etkisi

\begin{tabular}{|l|l|l|l|l|l|}
\hline ANOVA & $\begin{array}{c}\text { Kareler } \\
\text { toplamı }\end{array}$ & df & $\begin{array}{c}\text { Ort. } \\
\text { kare }\end{array}$ & F & Mem. \\
\hline $\begin{array}{l}\text { Gruplar } \\
\text { Arasında }\end{array}$ & 3,045 & 14 & 0,218 & 0,866 & 0,596 \\
\hline $\begin{array}{l}\text { Gruplar } \\
\text { İçinde }\end{array}$ & 53,723 & 214 & 0,251 & & \\
\hline Toplam & 56,769 & 228 & & & \\
\hline
\end{tabular}

\subsection{2. İSG Eğitiminin KKD Kullanımına Etkisi}

İSG eğitiminin verilmesi ile KKD kullanımı arasındaki ilişki, Ki Kare testi kullanılarak analiz edilmiştir. İSG eğitiminin KKD kullanımına etkisi ile ilgili hipotezler aşağıda verilmiştir.

$\mathrm{H}_{0}$ : Çalışanlara iş güvenliği eğitiminin doğru zamanda verilmesi ile KKD kullanımları arasında anlamlı bir ilişki yoktur.

$\mathrm{H}_{1}$ : Çalışanlara iş güvenliği eğitiminin doğru zamanda verilmesi ile KKD kullanımları arasında anlamlı bir ilişki vardır.

Çizelge 6'da verilen test sonuçları incelendiğinde (Sig. (p) 0,15>0,05) \%95 güven aralığında, çalışanlara iş güvenliği eğitiminin doğru zamanda (işbaşı öncesinde, yeni makine kullanımında, yer değişiminde ve en az yılda bir defa) verilmesinin KKD kullanımını etkilemediği sonucuna varılmaktadır.

Çizelge 6. İSG eğitiminin KKD kullanımına etkisi

\begin{tabular}{|c|c|c|c|}
\hline & Gözlemlenen & Beklenen & Kalan \\
\hline $1^{*}$ & 128 & 117,0 & 11,0 \\
\hline $2^{*}$ & 106 & 117,0 & $-11,0$ \\
\hline Toplam & 234 & & \\
\hline & & & \\
\hline & $\begin{array}{c}\text { KKD } \\
\text { Kullanımı }\end{array}$ & & \\
\hline Test & Ki-kare(a) & 2,068 & \\
\cline { 2 - 4 } İstatistiği & df & 1 & \\
\cline { 2 - 4 } & Asimp.Mem. & 0,150 & \\
\hline
\end{tabular}

a 0 hücre $(, 0 \%)$ 5'den düşük beklenen frekansa sahiptir. Beklenen en düşük hücre frekansı 117,0'dır.

1: KKD kullanma

*1:Eğitimin doğru zamanlarda verilmesi

2: KKD kullanmama

*2: Eğitimin doğru zamanlarda verilmemesi 


\subsubsection{ISG Denetim Sıklı̆ının KKD Kullanımına Etkisi}

İSG denetim sıklığı ile KKD kullanımı arasındaki ilişki, Anova testi kullanılarak analiz edilmiştir. İSG denetim sıklığının KKD kullanımına etkisi ile ilgili hipotezler aşağıda verilmiştir.

$\mathrm{H}_{0}$ : İş güvenliğgi ile ilgili denetimin sıklı̆̆ıyla çalışanların KKD kullanmaları arasında anlamlı bir ilişki bulunmamaktadır.

$\mathrm{H}_{1}$ : İş̧ güvenliği ile ilgili denetimin sıklığıyla çalışanların KKD kullanmaları arasında anlamlı bir ilişki bulunmaktadır.

İş güvenliği ile ilgili denetimin sıklığının, çalışanların KKD kullanımı üzerine etkisi incelendiğinde aşağıdaki sonuçlara ulaşılmıştır (Çizelge 7 (a) ve (b)):

İş güvenliği ile ilgili denetimin yapılmadığ 1 yerlerde, denetimin günlük olarak yapıldığ işyerlerine kıyasla daha az (mean difference 0,46947) KKD kullanılmaktadır.

İş güvenliği ile ilgili denetimin yapılmadığ 1 yerlerde, denetimin haftalık olarak yapıldığı işyerlerine kıyasla daha az (mean difference 0,29532) KKD kullanılmaktadır.
İş güvenliği ile ilgili denetimin yapılmadığı yerlerle denetimin aylık olarak yapıldığı yerler arasında, KKD kullanım oranları yönünden belirgin bir fark bulunmamaktadır.

İş güvenliği ile ilgili denetimin günlük olarak yapıldığ 1 yerlerde, denetimin aylık olarak yapıldığ 1 yerlere kiyasla daha fazla (mean difference0,26032) KKD kullanılmaktadır.

Analiz sonuçlarına göre; iş güvenliği ile ilgili denetimlerin sıklığı arttıkça, çalışanların KKD kullanım oranı da artmaktadır.

Çizelge 7. İSG denetim sıklı̆̆ının KKD kullanılmasına etkisi (a) ANOVA analiz sonuçları

\begin{tabular}{|l|c|c|c|c|c|}
\hline ANOVA & $\begin{array}{c}\text { Kareler } \\
\text { toplamı }\end{array}$ & df & $\begin{array}{c}\text { Ort. } \\
\text { kare }\end{array}$ & F & Mem. \\
\hline $\begin{array}{l}\text { Gruplar } \\
\text { Arasında }\end{array}$ & 6,299 & 3 & 2,100 & 9,416 & 0,000 \\
\hline $\begin{array}{l}\text { Gruplar } \\
\text { İçinde }\end{array}$ & 49,058 & 220 & 0,223 & & \\
\hline Toplam & 55,357 & 223 & & & \\
\hline
\end{tabular}

Çizelge 7(b). Çoklu karşılaş̧ırma sonuçları

\begin{tabular}{|c|c|c|c|c|c|c|c|}
\hline \multirow{2}{*}{ (2) } & \multirow{2}{*}{$\begin{array}{c}\text { (I) } \\
\text { Denetim }\end{array}$} & \multirow{2}{*}{$\begin{array}{c}(\mathbf{J}) \\
\text { Denetim }\end{array}$} & \multirow{2}{*}{$\begin{array}{l}\text { Ortalama } \\
\text { fark (I-J) }\end{array}$} & \multirow{2}{*}{$\begin{array}{l}\text { Std. } \\
\text { hata }\end{array}$} & \multirow{2}{*}{ Mem. } & \multicolumn{2}{|c|}{ 95\% güven aralığı } \\
\hline & & & & & & Alt sinır & Üst sınır \\
\hline Tukey HSD & 1,00 & 2,00 & ,46947(*) & ,09318 & ,000 & ,2282 & ,7107 \\
\hline & & 3,00 & ,29532(*) & 10540 & ,028 & ,0225 & ,5682 \\
\hline & & 4,00 & 20915 & 11293 & 252 &,- 0832 & ,5015 \\
\hline & 2,00 & 1,00 &,$- 46947(*)$ & ,09318 & ,000 &,- 7107 &,- 2282 \\
\hline & & 3,00 &,- 17415 & 08170 & , 146 &,- 3856 & 0373 \\
\hline & & 4,00 &,$- 26032(*)$ & ,09120 & ,024 &,- 4964 &,- 0242 \\
\hline & 3,00 & 1,00 &,$- 29532(*)$ & 10540 & ,028 &,- 5682 &,- 0225 \\
\hline & & 2,00 & ,17415 & ,08170 & , 146 &,- 0373 & ,3856 \\
\hline & & 4,00 &,- 08617 & , 10366 & ,840 &,- 3545 & , 1822 \\
\hline & 4,00 & 1,00 &,- 20915 & 11293 & 252 &,- 5015 & 0832 \\
\hline & & 2,00 & ,26032(*) & ,09120 & ,024 &, 0242 & ,4964 \\
\hline & & 3,00 & ,08617 & , 10366 & 840 &,- 1822 & ,3545 \\
\hline
\end{tabular}

* Ortalama fark, 0,05 düzeyinde anlamlıdır.

**Analizde KKD kullanmak 1, kullanmamak 2 olarak kodlanması nedeniyle mean difference değerleri ters yönde işlemektedir. ***Denetim sıklığında Denetim yapılmıyor :1, Günlük :2, Haftalık :3, Aylık :4. 


\section{SONUÇ VE ÖNERİLER}

\subsection{Sonuçlar}

$\mathrm{Bu}$ çalışmada yapım işlerindeki iş kazalarını önlemede en önemli etkenlerden biri olan; çalışanların KKD kullanımına etki eden faktörler belirlenmeye çalışılmış ve bu kapsamda inşaat sektöründe çalışanlara yönelik bir anket hazırlanmıştır. Anket çalışması sonucunda elde edilen veriler; geçmiş çalışmalardan sağlanan veriler ve yasal mevzuat da dikkate alınarak değerlendirilmiştir. Çalışma neticesinde elde edilen sonuçlar başlıklar halinde sunulmuştur.

\subsection{1. Çalışanların Yaşı}

Literatürde yer alan çalışmalarda iş kazaları ile çalışan yaşı arasında net bir bağlantı bulunmamakla birlikte, orta yaş grubunun en riskli grup olduğu ve genel olarak çalışan yaşının artması ile iş kazası geçirme oranının düştüğü görülmüştür.

Yapılan anket çalışmasında da çalışanların büyük çoğunluğunu orta yaş grubunun oluşturduğu tespit edilmekle birlikte çalışan yaşı ile iş kazalarını önlemek amacıyla KKD kullanımı arasında bir ilişski bulunamamıştır.

\subsection{2. İş Güvenliği Eğitimleri}

Önceki çalışmalardan elde edilen verilere göre iş güvenliği ile ilgili eğitim verilme oranı arttıkça, iş kazası meydana gelme riski azalmaktadır.

Yasal mevzuat hükümlerine göre çalışanlara; işe başlamalarından önce, iş veya çalışma yeri değişikliklerinde, iş ekipmanın değişmesi durumunda, yeni bir teknoloji uygulanması durumunda iş güvenliği eğitimi verilmesi ve yılda en az bir kez tekrarlanması zorunludur.

Ankete katılanların verdiği cevaplara göre iş güvenliği eğitiminin doğru zamanlarda verilmesi oranı çok düşüktür. Hipotez testleri analiz sonuçlarına göre doğru zamanlarda eğitim verilmesi, çalışanların KKD kullanımını fark ettirmemektedir.

\subsection{3. İş Güvenliği Denetimleri}

Önceki çalışmalarda iş güvenliği ile ilgili denetimlerin yeterli miktarda olmadığı, iş güvenliği denetim miktarı artan şantiyelerde iş güvenliği indeksinde artış olduğu görülmüştür.

Yasal mevzuata göre işverenin sorumluluklarından birisi de iş güvenliği ile ilgili denetimlerini yapmaktır. $\mathrm{Bu}$ sorumluluk işveren tarafından yetkilendirilen iş güvenliği uzmanları üzerinden gerçekleştirir. Yapılan işin cinsine ve işyerinde çalışan sayısına bağlı olarak görevlendirilecek iş güvenliği uzmanının sınıfı ve işyerinde bulunacağı süre belirlenmektedir.

Yapılan anket çalışmasında; inşaat sektöründe iş güvenliği denetim oranının çok düşük olduğu, bazı şantiyelerde hiç yapılmadığı, birçok şantiyede ise bu denetimlerin aylık yapıldığı tespit edilmiştir. Elde edilen verilere göre, iş güvenliği ile ilgili denetimlerin yetersiz olduğu görülmektedir.

Hipotez testi analiz sonucuna göre; iş güvenliği ile ilgili işyerlerinde yapılan denetim sıklığı arttıkça, KKD kullanım oranı da artış göstermektedir.

\section{2. Öneriler}

İnşaat sektörü, iş kazalarının en çok görüldüğü sektörler arasındadır. İnşaat sektöründe; yapım süresi boyunca inşaatın fiziksel şartlarının sürekli değişimine bağlı olarak, riskler de sürekli değişmektedir. Bu değişime bağlı olarak ortam güvenliğinin sağlanmasının çok zor olması nedeniyle, iş kazalarının önlenmesinde çalışanların KKD kullanımı çok önemlidir.

$\mathrm{Bu}$ çalışma sonucunda yapılan değerlendirmeye göre çalışanların KKD kullanımını etkileyen en önemli faktör iş güvenliği denetimidir. İş güvenliği ile ilgili yasal düzenlemeler yapılmış olmakla birlikte, mevzuatın etkili olarak uygulanabilmesi için iş güvenliği denetimleri arttırılmalıdır. İş güvenliği denetimi ile görevli çalışanların görevlerini daha etkin yapabilmeleri amacıyla; iş güvenliği uzmanı tam zamanlı istihdam edilmelidir. 
Yapım işlerinde çalışanların KKD kullanımına etki eden faktörlerle ilgili yapılan bu çalışmanın, çalışanların KKD kullanımının nasıl arttırılacağı konusunda faydalı olacağı düşünülmektedir.

\section{KAYNAKLAR}

1. Dorji, K., Hadikusomo, B.H.W., 2006. Safety Management Practices in the Bhutanese Construction Industry, Journal of Construction in Developing Countries, 11(2), 53-75.

2. Kuruoğlu, Y., Kuruoğlu, M., Bask1, H.G., Müngen, M.U., 2007. Fiziksel Güce Dayalı İnşaat İşlerinde Çalışanların İş Yaşamı, İş Sağlığı ve Güvenliğine Bağlı Performanslarının Değerlendirilmesi, İş Sağlığı ve Güvenliği Sempozyumu, Ankara. 289-299

3. Laitinen, H., Ruohomaki, I., 1996. The Effects of Feedback and Goal Setting on Safety Performance at Two Construction Sites, Safety Science, 24(1), 61-73.

4. Dikmen, S.Ü., Tüzer, F.S., Yiğit, S., 2011. 4857 Sayılı Yasa ve İnşaat Şantiyelerinde İş Sağlığı ve Güvenliği Yaklaşımları, Türkiye Mühendislik Haberleri, 469(5), 25-31.

5. Zhou, Q., Fang, D., Wang, X., 2008. A Method to Identify Strategies for the Improvement of Human Safety Behavior by Considering Safety Climate and Personal Experience, Safety Science, 46, 1406-1419.

6. Hassanein, A.A.G., Hanna, R.S., 2008. Safety Performance in the Egyptian Construction Industry, Journal of Construction Engineering and Management, June, 451-455.

7. Ho, C.L., Dzeng, R.J., 2010. Construction Safety Training Via e-Learning: Learning Effectiveness and User Satisfaction, Computers \& Education 55, 858-867.

8. Metinsoy, T., Müngen, U., 2011. İnşaat Sektöründe İş Güvenliği Yönetimi ve Genel İş Güvenliği Performansı İlişkisinin Değerlendirilmesi Yöntemi, 3. İşçi Sağlığı ve İş Güvenliği Sempozyumu, Çanakkale, 143-156.

9. Demirkesen, S., Arditi, D., Özorhon, B., 2013. İnşaat Sektöründe İş Güvenliği Eğitimi Uygulamaları, 4. İşçi Sağlığı ve İş Güvenliği Sempozyumu, Konya, 15.
10.Siu, O., Phillips, D.R., Leung, T., 2003. Age Differences in Safety Attitudes and Safety Performance in Hong Kong Construction Workers, Journal of Safety Research 34, 199 205.

11. Manisalı, E., Kanıt, R., Gündüz, M., Tarhan, Ü., Taşyürek, Y.E., 2007. İnşaat Sektöründe İş Sağlığ 1 ve Güvenliği Durumunun Değerlendirilmesi, İş Sağlı̆̆ı ve Güvenliği Sempozyumu, Ankara. 183-192

12. Güvel, Ş.T., 2016. İş Sağlığı ve Güvenliği Sisteminin Yapım İşlerinde Uygulanmasında Yaşanan Sıkıntılar ve Çözüm Önerileri”, Çukurova Üniversitesi Fen Bilimleri Enstitüsü, Doktora Tezi, Adana, 294.

13. Kişisel Koruyucu Donanımların İşyerlerinde Kullanılması Hakkında Yönetmelik (02.07.2013), No:28695, www.mevzuat.gov.tr, Erişim Tarihi:17.12.2020.

14. İş Sağlığı ve Güvenliği Hizmetleri Yönetmeliği (29.12.2012), No:28512, www.mevzuat.gov.tr, Erişim Tarihi:17.12.2020.

15. İş Sağlığı ve Güvenliği Kanunu (30.06.2012), No:6331, www.mevzuat.gov.tr, Erişim Tarihi:17.12.2020.

16. Yap1 İşlerinde İş Sağlığı ve Güvenliği Yönetmeliği (05.10.2013), No:28786, www.mevzuat.gov.tr, Erişim Tarihi: 17.12.2020.

17. Yap1 Müteahhitlerinin Sinıflandırılması ve Kayıtlarının Tutulması Hakkında Yönetmelik (02.03.2019), No:30702, www.mevzuat.gov.tr, Erişim Tarihi: 17.12.2020.

18. Şantiye Şefleri Hakkında Yönetmelik (02.03.2019), No:30702, www.mevzuat.gov.tr, Erişim Tarihi:17.12.2020.

19. İş Güvenliği Uzmanlarının Görev, Yetki Sorumluluk ve Eğitimleri Hakkında Yönetmelik (29.12.2012), No:28512, www.mevzuat.gov.tr, Erişim Tarihi:17.12.2020. 